\title{
Error feedback in second language speaking: Investigating the impact of modalities of error feedback on intermediate EFL students' speaking ability
}

\author{
Alireza Khoram ** (D), Ali Darabi Bazvandb (D), Jwamer Sarkawt Sarhadc \\ a English Department, Faculty of Letters and Humanities, Shahid Chamran University of Ahvaz, Ahvaz, Iran. \\ ${ }_{b}$ English Department, Faculty of Education, Halapche University, Halapche, Iraq \\ c National Institute for Technology, Sulaymaniyah, Iraq \\ Received 18 April 2019 | Received in revised form 27 December 2019 | Accepted 17 February 2020
}

\begin{abstract}
APA Citation:
Khoram, A., Darabi Bazvand, A., \& Sarkawt Sarhad, J. (2020). Error feedback in second language speaking: Investigating the impact of modalities of error feedback on intermediate EFL students' speaking ability. Eurasian Journal of Applied Linguistics, 6(1), 63-80.

Doi: 10.32601/ejal.710205
\end{abstract}

\begin{abstract}
Over the past few decades, error feedback has received substantial attention in language pedagogy. Despite this, few studies have been carried out on the effect and benefits of various modalities of error feedback on the oral proficiency of the intermediate EFL learners. To this end, an experimental design was adopted and implemented with 80 female high school students who were divided into four groups, namely, the intra-error feedback group (Intra-EF group), the inter-error feedback group (Inter-EF group), the teacher error feedback group (TEF group), and the control group. Treatment sessions for the experimental groups included three sessions for completing the speaking tasks and three sessions for feedback conferences. The participants in all groups completed the same speaking activities under the same process of discussion, but received different modalities of error feedback in feedback sessions. Results of T-test, one-way ANOVA and Scheffe Post Hoc test revealed that different stages of peer error feedback (i.e., intra- and inter-error feedback), as well as teacher error feedback influenced the learners' speaking ability. Additionally, peer error feedback and teacher error feedback exerted different effects on their speaking ability.

(C) 2020 EJAL \& the Authors. Published by Eurasian Journal of Applied Linguistics (EJAL). This is an open-access article distributed under the terms and conditions of the Creative Commons Attribution license (CC BY-NC-ND) (http://creativecommons.org/licenses/by-nc-nd/4.0/).
\end{abstract}

Keywords: Intra-error feedback; inter-error feedback; teacher feedback; speaking ability

\section{Introduction}

An extensive amount of investigation in second language acquisition (SLA) has been dealing with the function of classroom communication in SLA. It is assumed that throughout class conversations, students get comprehensible input, chances for

\footnotetext{
* Corresponding author. Tel.: +98-916-372-2056

E-mail address: arkhoram2017@gmail.com

http://dx.doi.org/10.32601/ejal.710205
} 
negotiation of meaning, and opportunities for the production of modified output (Egi, 2010; Loewen, 2015; Oliver, 1995; Swain, 1995). However, previous studies demonstrate that exposing the learners to input is not enough for learners to comprehensively attain the target language components (e.g., Afitska, 2012; Long, 1996; Norris \& Ortega, 2000; Sheen, 2008). This specifically relates to those characteristics which are semantically redundant, syntactically complicated and cognitively challenging (Ranta \& Lyster, 2007). To recompense for learners' deficiency to discern some facets of input, scholars have tried to make learners attend to some linguistic characteristics in the input which cause difficulties and problems for students (e.g., Gass \& Varonis, 1994; Long, 2007; Schmidt, 1990).

In the previous psychological studies, making error was regarded as an indicator of poor learning quality. Conventionally, instruction has perceived error as an indicator of the extent of the learners' failure and as a measure for assessing students. As Harmer (2007) observes, for learners, the concept of error was indeed associated with a shortcoming leading to a chain of unwanted results. Nowadays, the viewpoint has altered. Investigation into error is an invaluable basis for the learning process. As Harmer (2007) further asserts, it permits the instructor to enter into the different stages of the process of learning and to control or monitor it. In addition, errors assist as appropriate feedback for teachers on effectiveness of the selected teaching approaches, or possibly on their operational inadequacies, too.

Followed from the above, correction should not be assumed as disapproval or penalty for errors. According to Edge (1989), "correction is a way of reminding students of the forms of Standard English" (p. 20). When rectifying, teachers assist learners in becoming more correct in their L2 proficiency. It should not mean "insisting on everything being absolutely correct" (Edge, 1989, p. 33); in contrast, correction should be conceived of as a tool for aiding students on their route to grasping the L2, not as a means for accomplishing flawlessness. Meanwhile, given the separate parameters including settings, pronunciation, lexicon, and impetuosity as effective fragments in speaking, error rectification in speaking is greatly demanding and probably confounding. Therefore, some factors should be carefully taken into consideration for an effective rectification of the errors in speaking such as learners' level, types of errors and the timing of correction. For this purpose, a proper error correction method is required.

With regard to error correction, the effectiveness of corrective feedback on second language development has been widely deliberated by scholars within the last two decades. Some scholars (e.g., Allwright \& Bailey, 1991; Brown, 2007; Doughty \& Williams, 1998; Lyster, Saito \& Sato, 2013; Oliver \& Mackey, 2003; Sato, 2011) have focused on the role of interactional structure of classroom plays in helping learners to repair impasses in their conversational discourses. In this regard, teachers offer feedback in either oral or written form to increase learners' awareness of different kinds of errors they commit in the language classroom. In addition to teacher error feedback, peer error feedback has also gained ground recently. 
With a move from an educational approach to a learner-oriented paradigm towards language pedagogy, finding students' attitudes for correcting the speaking errors seems to be of crucial importance (Sheen, 2010). With such a shift, learner-oriented methods of error correction, including peer correction or self-correction have appeared. In this regard, peer correction is a choice for instructors transporting correction onto another learner. This typically arises when learners are incapable to self-correct (Sheen \& Ellis, 2011). Learners can support each other particularly with correctness and form, as Russell and Spada (2006) argue. With peer correction, however, it is essential to return to the learner who initially committed the error (Edge, 1989) to ensure s/he has understood what was incorrect at first place. Moreover, it is essential to make sure that it is not the same few learners who perform correction all the time: "The idea of peer correction is to encourage cooperation, not to put one or two students in the traditional place of the teacher" (Edge, 1989, p. 26). If these conditions are met, then peer correction can be helpful. In line with such arguments, there is an urgently felt need to investigate different stages of error feedback in an EFL context.

\section{Review of literature}

\subsection{Teacher error feedback}

Research into error correction originates from the move towards communicative language teaching with an emphasis on form (e.g. Norris \& Ortega, 2000), and from the long-established interactionist SLA tradition (e.g. Gass, Mackey \& Pica, 1998; Plonsky \& Gass, 2011). As this research movement develops, a plethora of classroom observational investigations have looked into the preferences teachers are likely to manifest in their oral feedback options across pedagogical environments (e.g. Li, 2010; Sheen, 2004), and to what degree diverse feedback kinds are perceived and absorbed by learners (Ellis, Basturkmen \& Loewen, 2001; Lyster \& Ranta, 1997). Both experimental and observational feedback studies look into the impacts of feedback on second language development, which is calculated by pre and posttests or the extent of uptake or repair in response to different sorts of feedback.

Research studies demonstrate that learners are in favor of error feedback from teachers since they think that feedbacks from teachers are significantly beneficial for them (Leki, 1991; Radecki \& Swales, 1988; Straub, 1997). Moreover, a number of studies have emphasized that feedback is advantageous to learners to perceive the gap between their non-target forms and the target forms (Chen \& Nassaji, 2018; Han, 2001; Li, 2014; Lyster, 1998; Lyster \& Ranata, 1997; Rassaei, 2013; Su \& Tian, 2016). Notwithstanding this yearning for detailed feedback on errors, there is a continuing argument in present literature whether error correction truly encourages the accuracy of students' performance. As previous investigations have produced inconclusive results regarding the effectiveness of teacher error feedback, it behooves us to canvass this topic further.

\subsection{Peer error feedback}


Peer feedback has captured the interests of L2 speaking researchers as it expedites learners' interlanguage development (Brown, 2014). A considerable number of studies have explored how peer feedback could influence different language skills (e.g., Lee \& Lyster, 2016; Lyster \& Saito, 2010; Saito \& Hanzawa, 2015; Sheen, 2004, 2011). Furthermore, notwithstanding the significant and long-term impacts of corrective feedback on language growth, the effectiveness of different modalities of feedback in affecting the process and outcome of second language speaking has received little attention within the teaching context in Iran. Hence, investigating the distinguishing effects of some types of feedback on EFL learners' English-speaking ability can add to experimental awareness on speaking training and to widen horizons in regard to the roles ascribed to feedback.

With regard to the different feedback modes in writing, Lee (2015) introduced the concepts of inter and intra feedback. Inter-feedback is the conventional practice mode in which the reviewers provide comments to and discusses the comments with writers. On the contrary, intra-feedback is conducted where two reviewers of the same compositions first present all of their written comments on the compositions and then confer with one another any possible differences or doubts in their comments, offering feedback on each other's feedback performance, and, if required, revise their own comments prior to offering them to the writers of the compositions. Meanwhile, in practical EFL speaking classes, different kinds of feedbacks are provided and according to Plonsky and Brown's (2016) meta-analysis findings, how to use feedback in various speaking tasks is critical. Therefore, in light of the Lee's (2015) framework for offering feedback to students and the lack of research on the role of inter- and intra-feedback practices in the oral proficiency of the learners, the current study attempts to fill the gap existent in previous investigations by scrutinizing the impact and the benefits of inter- and intra-feedback on the oral proficiency of the Iranian intermediate EFL learners. Thus, the study sought to answer the following questions:

1. To what extent do different stages of peer error feedback affect EFL learners' speaking ability?

2. To what extent does teacher error feedback affect EFL learners' speaking ability?

3. To what extent do peer error feedback (i.e., intra- and inter-error feedback) and teacher error feedback exert similar or different effects on EFL learners' speaking ability?

\section{Method}

\subsection{Research design}

The present study aims to make a comparison between the learners' oral performance before and after the treatment, i.e. speaking ability with three types of feedbacks (teacher error feedback, intra- and inter-error feedback). The present study employed a quasi-experimental design with pretest-posttest format. Two weeks prior to the experiment, pretesting was conducted. The treatment phase of the study was 
carried out in different occasions for different groups. An immediate posttest was administered to compare the performance of the participants.

\subsection{Participants}

The participants in the present study were recruited from a pool of 118 female students in four intact classes enrolled in a public high school in Ahvaz, Iran. Those scoring one standard deviation above or below the mean in the proficiency test were excluded from the study. The researchers had to exclude some students from the analysis: 6 students did not attend all the tests and treatment sessions; and 32 students obtained scores of one standard deviation above or below the mean in the homogeneity test. Hence, 38 participants were excluded from the original pool of the participants and a total of 80 intermediate-level female learners remained in the study. They were divided into four groups: the intra-error feedback group (Intra-EF group), the inter-error feedback group (Inter-EF group), the teacher error feedback group (TEF group), and the control group.

\subsection{Instrumentation}

In order to homogenize the participants of the current study, the Oxford Placement Test (OPT) was administered. This test consists of 60 multiple-choice items. The mean score and standard deviation of the participants were 28.86 and 2.12 , respectively. Having conducted the homogeneity test, i.e., OPT, researchers administered the pretest to measure the participants' oral proficiency. Each interview took about 5 minutes. In order to validate the data and to check the inter-rater reliability of the pretest, the researchers asked a colleague, who was an MA holder in TEFL, to review the data. The inter-rater reliability index calculated through Pearson Correlation was 0.84. The index of obtained reliability was significant at the 0.01 level.

In order to score the participants' speaking performance in both pre-test and posttest, the checklist of speaking adapted from Hughes (2003) was employed. The checklist includes six scales for measuring speaking ability: fluency, comprehension, communication, vocabulary, structure, and accent. For each part, the lowest possible score is 1 and the highest possible score is 5. Therefore, based on Hughes' (2003) checklist, the total possible score ranges from 6 to 30. Moreover, to elicit students' speech, the researcher used three problem solving tasks which were designed based on three common problems, i.e., noisy neighbors, relationships, and traffic.

\subsection{Data collection procedure}

At the outset of the study, a pilot test was administered to 20 students who were analogous to the target participants of the study in terms of language proficiency. A problem solving task and a planned interview were carried out. In fact, the pilot test served as a rough estimate of the sufficient time to carry out the tasks, as well as the interview for each participant. The estimated time for completing the problem solving 
task was 6 to 10 minutes, and that for conducting interview for each participant was 3 to 5 minutes.

Two weeks prior to the experiment, pretesting was conducted. The researchers administered a planned interview in the form of question and answer, which was conducted individually. In order to safely measure the participants' speaking, all interviews were tape recorded. This instrument was designed to confirm the similarity of the experimental and control groups in terms of their speaking ability prior to the experiment.

Given that this study was conducted in a public high school, exact randomization of individuals was not possible. To account for this limitation of true-randomization, the researchers had to employ semi-randomization procedure in order to deal with nonrandomization of individuals through undertaking the study in four intact classes. The 80 participants were assigned to 4 groups of 20 each: intra-error feedback group (Intra-EF group), inter-error feedback group (Inter-EF group), teacher error feedback group (TEF group), and no error feedback group (NEF group) served as the control [CO] group.

The treatment phase of the study was carried out in different number of sessions for different groups: the study was conducted in nine sessions for the participants in the [TEF] group, in 10 sessions for the participants in the [Intra-EF] and [Inter-EF] groups, and in six sessions for the participants in the [CO] group. Treatment sessions for the experimental groups, i.e., [TEF] group, [Intra-EF] group, and [Inter-EF] group, included three sessions for completing the speaking activities (hereafter task sessions), and three sessions for feedback conferences (hereafter feedback sessions). Yet, the participants in intra-error feedback and inter-error feedback groups attended one extra session, during which they were guided via the objectives and techniques of inter- and intra-feedback through training and modeling and with the aid of a feedback sheet. The instruction for illustrating peer intra- and inter-feedback was designed based on feedback sheet developed by the researcher.

During the treatment sessions, participants in all groups completed the same problem solving tasks. In each session, one task was carried out. In order to make a discussion developmental and increasingly inclusive, we followed Brookfield and Preskill's (1999, pp.110-111) suggested process called "snowballing" or "pyramiding". In this process, as Brookfield and Preskill explain, the students begin the activity by responding to a handout of questions or issues as individuals. Hence, based on this procedure for discussion, the participants in the present study gathered their thoughts on problem solving tasks in private reflection and wrote down any notes. After five minutes of solitary thought, paired students began a dialogue on the tasks. After another five minutes, two pairs were combined to form a group of four and discussed the task in front of the class.

The participants in all groups completed the same speaking activities under the same process of discussion, yet the participants in different experimental groups received different modalities of error feedback in feedback sessions as follows: 
a. The participants in teacher error feedback group, TEF group, received feedback on their speech from the teacher. For this group, the researchers developed a feedback sheet, which was employed by teachers to provide more valid feedback to participants' speech. The feedback sheet consists of twelve5scale Likert evaluative statements which encompass three sections: (a) evaluation of the introduction of the participants' speech, (b) evaluation of the body of the participants' speech, and (c) evaluation of the language of the participants' speech. The researchers adapted the evaluation statements for the introduction and body sections from www.mtholyoke.edu/go/saw, 538-3428 and those for the language section were adapted from Hughes' (2003) checklist for measuring communicative abilities. In task sessions, while the groups were completing the task in front of the class, the teacher completed the feedback sheet for each participant. In feedback sessions, the teacher offered comments to and discussed the comments with each participant individually.

b. The participants in peer inter-error feedback group, [Inter-EF] group, received feedback on their speech from their peers. Given that the participants of this study were intermediate learners who could hardly use an English feedback sheet, a Persian version of the teacher feedback sheet was employed by students who were supposed to offer feedback to their peers. In task sessions, while the groups of two learners were completing the task in front of the class, the researchers delivered the peer version of the feedback sheet among other participants (hereafter peer evaluators) who were assessing the two task performers individually. Each peer evaluator randomly evaluated one of her peers' speeches through completing the feedback sheet. In feedback sessions, the peer evaluators offered comments to and discussed the comments with the specific participant whom they evaluated in task sessions.

c. The participants in peer intra-error feedback group, [Intra-EF] group, also received feedback on their speech from their peers. In task sessions, while the two students were completing the task in front of the class, the researchers delivered the peer version of the feedback sheet among other 18 participants, i.e., peer evaluator; however, each participant's speech was evaluated by two peer evaluators. For this group, feedback session consisted of two phases: in phase 1, two peer evaluators of the speech of the same student first presented all of their written comments on their classmate's speech to one another. The evaluators then conferred about any possible incongruities or disagreements in their comments, and provided feedback on each other's feedback presentation, and, if needed, modified their individual comments. In phase 2 of feedback sessions, these two peer evaluators presented their joint feedback to the student whose speech has been evaluated.

d. The participants of the control group, [CO] group, did not get feedback on their speaking performance. The treatment for this group included only three task sessions, during which the groups completed the task in front of the class. 


\begin{tabular}{llllll}
\hline \multirow{2}{*}{ Inter EF } & Pretest & 10.40 & 20 & 1.95 & .43 \\
& Posttest & 12.05 & 20 & 2.68 & .60 \\
\hline
\end{tabular}

As displayed in Tables 3 and 4, there is a significant difference in performance between the mean scores of speaking for Intra-EF $(\mathrm{M}=2.95, \mathrm{SD}=1.57)$ and Inter-EF $(\mathrm{M}=1.65, \mathrm{SD}=1.13)$ on the pretest and posttest; $\mathrm{t}=8.39$ for Intra-EF and $\mathrm{t}=6.49$ for Inter-EF, $p=.000$. This amount of t-value obtained is higher than the critical $t$-value of, i.e., 2.53 for both groups. These results suggest that there is a significant difference between the mean scores of speaking for both groups on the pretest and posttest. Therefore, different stages of peer error feedback (i.e., intra- and inter-error feedback) influence EFL learners' speaking ability.

In order to answer the second research question, and to check if there is any difference between speaking ability of the participants in TEF and control groups on posttest, two Paired-Samples t-tests were run. The descriptive statistics for the Paired-Samples t-tests in TEF group are displayed in Tables 5.

Table 5. Descriptive statistics for pretest and posttest of speaking in TEF group

\begin{tabular}{llllll}
\hline & & Mean & $\mathrm{N}$ & Std. Deviation & Std. Error Mean \\
\hline \multirow{2}{*}{ TEF } & Pretest & 11.40 & 20 & 1.95 & .43 \\
\cline { 2 - 6 } & Posttest & 15.45 & 20 & 2.68 & .60 \\
\hline
\end{tabular}

As shown in Table 5, there is a big difference between the mean scores of speaking for TEF group from pretest $(M=11.40)$ to posttest $(M=15.45)$.

Table 6 shows the descriptive statistics for the Paired-Samples t-tests in control group As shown in Table 6, there is not a significant difference between the mean scores of speaking for control group from pretest $(M=11.5)$ to posttest $(M=11.80)$.

Table 6. Descriptive statistics for pretest and posttest of speaking in control group

\begin{tabular}{llllll}
\hline & & Mean & N & Std. Deviation & Std. Error Mean \\
\hline \multirow{2}{*}{ CONTROL } & Pretest & 11.55 & 20 & 2.25 & .50 \\
& Posttest & 11.80 & 20 & 2.64 & .59 \\
\hline
\end{tabular}

Table 7 illustrates the results of the two Paired-Samples t-tests, which were run to reveal the difference between speaking ability of the participants in TEF and control groups on posttest

Table 7. Paired-samples t-test for pretest and posttest in TEF group

\begin{tabular}{|c|c|c|c|c|c|c|c|c|c|}
\hline & & \multicolumn{5}{|c|}{ Paired Differences } & \multirow[t]{3}{*}{$\mathrm{T}$} & \multirow[t]{3}{*}{$\mathrm{df}$} & \multirow{3}{*}{$\begin{array}{l}\text { Sig. (2- } \\
\text { tailed) }\end{array}$} \\
\hline & & \multirow[t]{2}{*}{ Mean } & \multirow[t]{2}{*}{$\begin{array}{l}\text { Std. } \\
\text { Deviation }\end{array}$} & \multirow[t]{2}{*}{$\begin{array}{l}\text { Std. Error } \\
\text { Mean }\end{array}$} & \multicolumn{2}{|c|}{$\begin{array}{l}95 \% \text { Confidence Interval of } \\
\text { the Difference }\end{array}$} & & & \\
\hline & & & & & Lower & Upper & & & \\
\hline TEF & $\begin{array}{c}\text { Pretest - } \\
\text { Posttest }\end{array}$ & 4.05 & 1.27 & .28 & 3.45 & 4.64 & 14.19 & 19 & .00 \\
\hline
\end{tabular}

As displayed in Table 7, there is a meaningful difference between the mean scores of speaking for TEF group $(\mathrm{M}=4.05, \mathrm{SD}=1.27)$ and control group $(\mathrm{M}=.25, \mathrm{SD}=.96)$ on 
the pretest and posttest; $\mathrm{t}=14.19$ for TEF and $\mathrm{t}=1.12$ for control group. The amount of $t$-value obtained is higher than the critical $t$-value, i.e., 2.53 for TEF group and lower than the critical t-value for control group. Based on these results, it can be safely concluded that there is a significant difference between the mean scores of speaking for TEF group on the pretest and posttest. Considering the control group, it can be argued that although there is a meaningful difference between the mean scores of speaking for control group on both the pretest and posttest, the difference is not significant. Thus, teacher error feedback had an effect on EFL learners' speaking proficiency.

In order to attend to the third research question, raised to investigate the difference between participants' speaking ability, the gained scores of the participants were calculated, and then a one-way ANOVA applying a between and within subject design was run to compare the improvement from pretest to posttest for the participants in TEF, Intra-EF, and Inter-EF groups. Treatment condition was the between-subject factor (TEF, Intra-EF, and Inter-EF), and gained score was the within-subject factor.

The descriptive statistics for the gained scores of the participants in TEF group, Intra-EF group, and Inter-EF group in terms of their speaking ability are displayed in Table 8.

Table 8. Descriptive statistics for gained score of speaking

\begin{tabular}{|c|c|c|c|c|c|}
\hline & GROUP & $\mathrm{N}$ & Mean & Std. Deviation & Std. Error Mean \\
\hline \multirow{2}{*}{$\begin{array}{l}\text { GAINED } \\
\text { SCORE }\end{array}$} & TEF & 20 & 4.05 & 1.27 & .28 \\
\hline & Intra-EF & 20 & 2.85 & 1.63 & .36 \\
\hline \multirow{2}{*}{ PRETEST } & Inter-EF & 20 & 1.65 & 1.13 & .25 \\
\hline & Control & 20 & .35 & 1.13 & .25 \\
\hline
\end{tabular}

Table 9 indicates the results of the one-way ANOVA, run to prove the improvement from pretest to posttest for the participants in [TEF] group, [Intra-EF] group, and [Inter-EF] group in terms of their speaking ability.

Table 9. ANOVA for gained score in TEF, Intra-EF, Inter-EF, and control groups

\begin{tabular}{llllll}
\hline & Sum of Squares & $\mathrm{df}$ & Mean Square & F & Sig. \\
\hline Between Groups & 151.35 & 3 & 50.45 & 29.35 & .000 \\
Within Groups & 130.60 & 76 & 1.71 & & \\
Total & 281.95 & 79 & & & \\
\hline
\end{tabular}

As shown in Table 9, there is a meaningful difference between the three groups' gained scores $[\mathrm{F}(3,76)=29.35, \mathrm{p}=.000]$.

Furthermore, a Tukey post hoc test was conducted to determine the direction of the difference between all groups (i.e., TEF group, Intra-EF group, Inter-EF group, and the control group) in terms of their oral performance (see Table 10).

Table 10. Scheffe post hoc for speaking 


\begin{tabular}{lllllll}
\hline (I) VAR00004 & (J) VAR00004 & Mean Difference & Std. Error & Sig. & \multicolumn{2}{c}{$95 \%$ Confidence Interval } \\
& & (I-J) & & & Lower Bound & Upper Bound \\
\hline \multirow{3}{*}{ TEF } & Intra-EF & $1.20^{*}$ & .41 & .046 & .014 & 2.38 \\
& Inter-EF & $2.40^{*}$ & .41 & .000 & 1.21 & 3.58 \\
& CONTROL & $3.70^{*}$ & .41 & .000 & 2.51 & 4.88 \\
& TEF & $-1.20^{*}$ & .41 & .046 & -2.38 & -.01 \\
Intra-EF & Inter-EF & $1.20^{*}$ & .41 & .046 & .01 & 2.38 \\
& CONTROL & $2.50^{*}$ & .41 & .000 & 1.31 & 3.68 \\
& TEF & $-2.40^{*}$ & .41 & .000 & -3.58 & -1.21 \\
Inter-EF & Intra-EF & $-1.20^{*}$ & .41 & .046 & -2.38 & -.014 \\
& CONTROL & $1.30^{*}$ & .41 & .025 & .11 & 2.48 \\
& TEF & $-3.70^{*}$ & .41 & .000 & -4.88 & -2.51 \\
CONTROL & INTRA & $-2.50^{*}$ & .41 & .000 & -3.68 & -1.31 \\
& Inter-EF & $-1.30^{*}$ & .41 & .025 & -2.48 & -.11 \\
\hline
\end{tabular}

*. The mean difference is significant at the 0.05 level.

As the results displayed in Table 10 reveal, the main effect for error feedback was related to these contrasts: (a) [TEF] group performed significantly better than [Intra$\mathrm{EF}$ ], [Inter-EF] groups, and control group; (b) [Intra-EF] group performed significantly better than [Inter-EF] group, and control group; and (c) [Inter-EF] group over performed the control group significantly.

In sum, these results suggest that different stages of peer error feedback (i.e., intraand inter-error feedback), as well as teacher error feedback affect learners' speaking ability. Peer error feedback and teacher error feedback exert different effects on learners' speaking ability. Furthermore, the teacher's provision of feedback is more effective than exposing learners to Intra-error feedback, which is more effective than Inter-error feedback, in turn.

\section{Discussion}

This study sought to make a contribution to second language education by investigating a less explored issue pertaining to how three oral feedback types (inter, intra, and TEF) generate differential outcomes of L2 development. The first important finding in the current study is that the participants enhanced their speaking ability with the aid of feedback.

Regarding the first research question, the results showed that there was a significant difference in performance between the mean scores of speaking for both groups (Intra \& Inter) on the pretest and posttest. It was found that intra- and intererror feedback had an effect on students' speaking ability. Peer correction created a learning-focused orientation with a constructive atmosphere across peer feedback activities and the learners benefited from each other's comments. This finding corroborates the research conducted in this area (e.g., Lin, 2009). When learners take part in meaningful discussion with their peers, this will empower them to achieve higher levels of performance than they could have achieved on their own (Lin, 2009; Min, 2005). 
One potential explanation for the findings obtained from the present study is that it involves learners working collaboratively and actively rectifying each other's error then providing feedback to their peers. Learners work in a collaborative dynamic that lets them receive feedback that can influence positively on their speaking skills over time (Panova \& Lyster, 2002). Another possible explanation for the current findings is congruent with Chastain (1988), arguing that foreign language learners need explicit instructions in speaking, like any other language skill. Such interactive activities on the part of students provide a good chance for them to change thoughts to speech.

The data presented in the present study reinforce some of the previously discussed issues conducted on peer feedback (e.g., Nicholas, Lightbown \& Spada, 2001; Rahimi \&Vahid Dastjerdi, 2012; Tsang, 2004; Yoshida, 2010). Results of both groups revealed that the students' speaking accuracy improved after receiving feedback. This seems to confirm the effectiveness of explicit feedback when used to correct the learners' inaccuracies (Ellis, 2009; Li, 2010). The results of the study are also consistent with those conducted by Margolis (2007) as well as Dong (2012). They concluded that advanced L2 learners made further gains in accuracy as a result of focused spoken feedback compared to unfocused feedback. However, the findings of this study revealed that overall spoken accuracy is somehow affected by both inter- and intrafeedback. That is, on a range of linguistic structures such as past tense, subject-verb agreement, articles and prepositions that students received as feedback, they produced fewer errors in their new speaking tasks.

The second question of the study was to determine the impact of teacher error feedback on the EFL learners' speaking ability. The findings refer to a significant difference of speaking ability between the mean scores for TEF group on the pretest and posttest. This finding chimes with the previous studies (Chehr Azad, Farrokhi, \& Zohrabi, 2018; Chu, 2011; Gumbaridze, 2013; Rassaei, 2013, Rassaei \& Moinzadeh, 2014; Lyster, Saito \& Sato, 2013; Wang, 2014) which revealed that teacher error correction helps students improve their accuracy in speaking, particularly when it targets and assesses specific forms. Error feedback entails negotiation of meaning between the learner and the teacher, necessitating learners' modified output and greater attention to the linguistic structures. This can enhance L2 acquisition by providing learners with both positive and negative evidence (Ellis, Loewen \& Erlam, 2006; Li, 2010; Russell \& Spada, 2006; Sato \& Lyster, 2012). Moreover, consistent with Schmidt's (1990, 1995, 2001) Noticing Hypothesis, it can be explained that in the present research context, ELT teachers seem to believe that if a teacher pinpoints grammatical inaccuracies in students' speaking, students would identify their errors, better notice and revise their incorrect forms and not repeat them in their future performance. The positive impacts of teacher feedback in posttests coincide with the above-alluded viewpoint that attention plays an integral role in L2 acquisition, prompting learners to direct their attention towards a mismatch between the learner's own interlanguage form and the target input. As Gass and Varonis (1994) argue, interactional feedback essentially help the learner focus on the parts of the 
discourse that causing productive or receptive problems, so that they could notice a gap between what is produced by L2 speakers and what they produce/know.

As for the third research question regarding the impact of peer error feedback (i.e., intra- and inter-error feedback) vis-à-vis teacher error feedback on learners' speaking ability, it was found that there was a meaningful difference between the three groups' gained score with the more influential effect of teacher feedback than the other groups. TEF group significantly outperformed Intra-EF, Inter-EF groups, and control group; Intra-EF group performed significantly better than Inter-EF group, and control group; and Inter-EF group performed significantly better than the control group. The findings suggest that peer evaluators were more engaged in correcting as a result of intra-feedback because they discussed the speaking comments with another helper. The exchange with others on the same student's speech performance made them treat peer feedback more seriously. Furthermore, intra-feedback may not only guide students to act with an eye toward monitoring and improving the quality of their own comments, but it may assist them to consider the difficulties in relation to giving feedback. This may subsequently increase their ability and awareness for selfregulation in evaluating (Lee, 2015). This mitigated peer feedback problems in quality and resulted in the evaluators and speakers' cognitive benefits of peer feedback.

This study's findings support the idea of providing different students with different kinds of feedback as claimed by researchers (e.g., Ellis, 2007; Loewen \& Nabei, 2007; Lyster, Saito \& Sato, 2013; Mackey, 2006; McDonough, 2005; Nassaji, 2009; Tedick \& de Gortari, 1998). Meanwhile, the findings show that by connecting input, internal learner capacities, and output in productive ways, the teacher's provision of feedback has helped enhance students' inter-language development (Long, 1996), and also supports interactions in L2 development as an empirical evidence sought by researchers (Mackey, 1999) and production (Gass \& Varonis, 1994; Gurzynski-Weiss \& Revesz, 2012). Moreover, the findings offer support to the notion that language teachers should deploy diverse strategies to rectify students' linguistic errors (Simard \& Jean, 2011).

In closing, it can be suggested that most of the peers can give feedback to their classmates' errors appropriately by understanding the subject matter and their proficiency level. This can be done when students are trained and given guidance and support. As Berg (1999) stated, "training is important for successful peer response" (p. 230).

\section{Conclusion and future directions}

This study aimed to determine the impact and the benefits of inter- and intrafeedback on the oral proficiency of the EFL learners. In line with previous research, the present study's findings showed that L2 learners' speaking ability benefits from different modalities of error feedback and that the proposed inter- and intra-feedback practice was well productive. These findings seem to support the different theoretical bases that underpin this study. In the present study, teacher error correction 
feedback (both direct and indirect) is seen as a form of spoken messages providing a source of comprehensible input to the learner. Thus, it can be considered as a base which helps them to acquire more competence and improve their speaking proficiency. More importantly, the findings raise awareness of the roles teachers play in assisting the learners by implementing innovative ways to augment their oral performance accuracy.

Peer feedback activities were effective for EFL students and incorporated teacher feedback because the teacher was deemed to be the expert and the only source of authority. This finding underscores the importance of continual error correction by L2 speaking teachers (Kai \& Tongshun, 2015; Li, 2010; Lyster \& Ranta, 2013). Therefore, it can be concluded that students cannot be considered as good judges of their own needs. That is, students value teachers' error feedback and consider it extremely important to their success.

Notwithstanding the abovementioned positive findings, the present study suffered from some limitations that need to be seriously taken in future research. The first limitation concerns the length of treatment which was relatively short in this study. Another limitation of the study is that true randomization of the participants was not feasible since they had already enrolled in the appropriate classes based on the high school's rules and policies. The other limitation is related to the gender, age, and proficiency level of the participants.

Regarding the pedagogical implications, the suggestion is that language teachers familiarize their high school EFL students as well as elementary and preintermediate language learners with privileges of giving feedback to sharpen their fervor so as to promote their speaking ability. Since this study manifested that teacher and peer feedback was useful for EFL students, explicit instruction on the use of these types of feedback is recommended for language teachers. Therefore, after the introducing the proper strategies to language teachers, teacher trainers must provide some instruction on how and when to utilize these strategies, specifically error feedback modalities for enhancing the speaking skill. Subsequent to getting acquainted with the types of feedback, they should be highly recommended to employ and teach them at suitable levels of language learning, taking their language learners' cognitive development into account.

Finally, based on the findings of the present study, several areas of research are put forward. First, there is a pressing need for additional studies that separate the diverse factors that could affect the provision of feedback in a coherent, efficient manner. As a further step, students' reactions to the type of error feedback could be investigated in future research. This can be done by including the same students' performance for not only one semester but for the whole academic year. Using various measurement tasks to investigate the degree to which various feedback types have differing effects on other aspects of speaking ability is also recommended for further research. Besides, future researchers may analyze different types of students' pragmatic competence (such as requesting, suggesting, thanking etc.), while 
interacting with each other in inter-error feedback and teacher-error feedback and the results of such interactions on revision mode and speaking proficiency.

\section{References}

Afitska, O. (2012). Role of focus-on-form instruction, corrective feedback and uptake in second language classrooms: Some insights from recent second language acquisition research. The Language Learning Journal, 43(1), 1-17.

Berg, E. C. (1999). The effects of trained peer response on ESL students' revision types and writing quality. Journal of Second Language Writing, 8(3), 215-241.

Brookfield, S. D., \& Preskill, S. (1999). Discussion as a way of teaching. San Francisco: Jossey Bass Publishers.

Brown, H. D. (2007). Teaching by principles. White Plains: Pearson Education.

Brown, H. D. (2014). The type and linguistic foci of oral corrective feedback in the L2 classroom: A meta analysis. Language Teaching Research, 29, 27-32.

Chastain, K. (1988). Developing second language skills: Theory and practice. Florida: Harcourt Brace Jovanovich Incorporation.

Chehr Azad, M., H., Farrokhi, F., \& Zohrabi, M. (2018). The effect of corrective feedback on Iranian EFL learners' spoken repair fluency and its relationship with spoken complexity and accuracy. International Journal of English Language and Translation Studies, 6(1), 38-47.

Chen, S., \& Nassaji, H. (2018). Focus on form and corrective feedback research at the University of Victoria, Canada. Language Teaching, 51( 2), 278-283.

Chu, R. (2011). Effects of teacher's corrective feedback on accuracy in the oral English of English-majors college students. Theory and Practice in Language Studies, 1(5), 454459 .

Dong, Z. (2012). Beliefs and practices: A case study on oral corrective feedback in the teaching Chinese as a Foreign Language (TCFL) classroom (Unpublished master's thesis). Arizona State University, AZ, USA.

Doughty, C., \& Williams, E. (1998). Communicative focus on form. In C. Doughty \& J. Williams (Eds.), Focus on form in classroom second language acquisition (pp. 114-138). Cambridge: Cambridge University Press.

Edge, J. (1989). Mistakes and correction. Harlow: Longman.

Egi, T. (2010). Uptake, modified output, and learner perceptions of recasts: Learner responses as language awareness. Modern Language Journal, 94, 1-21.

Ellis, R. (2007). The differential effects of corrective feedback on two grammatical structures. In A. Mackey (Ed.), Conversational interaction in second language acquisition: A series of empirical studies (pp.339-360). Oxford: Oxford University Press.

Ellis, R. (2009). Corrective feedback and teacher development. L2 Journal, 1, 3-18.

Ellis, R., Basturkmen, H., \& Loewen, S. (2001). Learner uptake in communicative ESL lessons. Language Learning, 51, 281-318.

Ellis. R., Loewen, S., \& Erlam, R. (2006). Implicit and explicit corrective feedback and the acquisition of L2 grammar. Studies in Second Language Acquisition, 28, 339-358.

Gass, S. M., Mackey, A., \& Pica, T. (1998). The role of input and interaction in second language acquisition. The Modern Language Journal, 82, 299-307.

Gass, S. M., \& Varonis, E. M. (1994). Input, interaction, and second language production. Studies in Second Language Acquisition, 16, 283-302. 
Gumbaridze, J. (2013). Error correction in EFL speaking classrooms. Social and Behavioral Sciences, 70, 1660-1663.

Gurzynski-Weiss, L. \& Revesz, A. (2012). Tasks, teacher feedback, and learner modified output in naturally occurring classroom interaction. Language Learning, 62, 851-879.

Harmer, J. (2007). How to teach English. Harlow: Pearson Education Limited: Longman.

Hughes, A. (2003). Testing for language teachers (2nd Ed.). Cambridge: Cambridge University Press.

Kai, Z., \& Tongshun, W. (2015). A review of studies on corrective feedback in interaction. Journal of Ocean University of China, 2, 116-121.

Lee, M. K. (2015). Peer feedback in second language writing: Investigating junior secondary students' perspectives on inter-feedback and intra-feedback. System, 55, 1 10.

Lee, A. H., \& Lyster, R. (2016). Effects of different types of corrective feedback on receptive skills in a second language: A speech perception training study. Language Learning, $66,1-25$.

Leki, I. (1991). The preference of ESL students for error correction in college-level writing classes. Foreign Language Annals, 24, 203-218.

Li, S. (2010). The effectiveness of corrective feedback in SLA: A meta-analysis. Language Learning, 60(2), 309-365.

Li, S. (2014). Oral corrective feedback. ELT Journal, 68(2), 196-198.

Lin, H. H. (2009). Patterns of corrective feedback and learner uptake in ESL low, intermediate, and advanced level speaking classroom. Unpublished doctoral dissertation, Alliant International University, San Diego, CA, USA

Loewen, S. (2015). Introduction to instructed second language acquisition. New York, NY: Routledge.

Loewen, S., \& Nabei, T. (2007). Measuring the effects of oral corrective feedback on L2 knowledge. In A. Mackey (Ed.), Conversational interaction in second language acquisition: A collection of empirical studies (pp. 361-376). Oxford: Oxford University Press.

Long, M. (1996). The role of the linguistic environment in second language acquisition. In W. C. Ritchie \& T. K. Bhatia (Eds.), Handbook of second language acquisition (pp. 413-468). San Diego, CA: Academic Press.

Long, M. H. (2007). Problems in SLA. Mahwah, NJ: Lawrence Erlbaum.

Lyster, R. (1998). Recasts, repetition, and ambiguity in L2 classroom discourse. Studies in Second Language Acquisition, 20, 51-81.

Lyster, R., \& Ranta, L. (1997). Corrective feedback and learner uptake: Negotiation of form in communicative classrooms. Studies in Second Language Acquisition, 19(1), 37-66.

Lyster, R., \& Ranta, L. (2013). Counterpoint piece: The case for variety in corrective feedback research. Studies in Second Language Acquisition, 35(1), 167- 184.

Lyster, R., \& Saito, K. (2010). Oral feedback in classroom SLA: A meta-analysis. Studies in Second Language Acquisition, 32, 265-302.

Lyster, R., Saito, K., \& Sato, M. (2013). Oral corrective feedback in second language classrooms. Language Teaching, 46, 1-40.

Mackey, A. (1999). Input, interaction, and second language development: An empirical study of question formation in ESL. Studies in Second Language Acquisition, 21, 557-587.

Mackey, A. (2006). Feedback, noticing and instructed second language learning. Applied Linguistics, 27, 405-430. 
Margolis, D. P. (2007). Impacts of oral error feedback in Korean university EFL classrooms. Unpublished doctoral dissertation, University of Hawaii at Manoa, Honolulu, HI, USA.

McDonough, K. (2005). Identifying the impact of negative feedback and learners' responses on ESL question development. Studies in Second Language Acquisition, 27, 79-103.

Min, H. (2005). Training students to become successful peer reviewers. System, 33, 293-308.

Nassaji, H. (2009). Effects of recasts and elicitations in dyadic interaction and the role of feedback explicitness. Language Learning, 59, 411-452.

Nicholas, H., Lightbown, P., \& Spada, N. (2001). Recasts as feedback to language learners. Language Learning, 51, 719-758.

Norris, J. M., \& Ortega, L. (2000). Effectiveness of L2 instruction: A research synthesis and quantitative meta-analysis. Language Learning, 50, 417-528.

Oliver, R. (1995). Negative feedback in child NS-NNS conversation. Studies in Second Language Acquisition, 17, 459-481.

Oliver, R., \& Mackey, A. (2003). Interactional context and feedback in child ESL classrooms. Modern Language Journal, 87, 519-533.

Panova, I., \& Lyster, R. (2002). Patterns of corrective feedback and uptake in an adult ESL classroom. TESOL Quarterly, 36, 573-595.

Plonsky, L., \& Brown, D. (2016). Domain definition and search techniques in meta-analyses of L2 research (Or why 18 meta-analysis of feedback have different results). Second Language Research, 31, 267-278.

Plonsky, L., \& Gass, S. (2011). Quantitative research methods, study quality, and outcomes: The case of interaction research. Language Learning, 61, 325-366.

Radecki, P., \& Swales, J. (1988). ESL student reaction to written comments on their written work. System, 16, 355-365.

Rahimi, A., \& Vahid Dastjerdi, H. (2012). Impact of immediate and delayed error correction on EFL learners' oral production: CAF. Mediterranean Journal of Social Sciences, 3(1), 4554.

Ranta, L., \& Lyster, R. (2007). A cognitive approach to improving immersion students' oral language abilities: The awareness-practice-feedback sequence. In R. M. DeKeyser (Ed.), Practice in a second language: Perspectives from applied linguistics and cognitive psychology (pp. 141-160). Cambridge: Cambridge University Press.

Rassaei, E. (2013). Corrective feedback, learners' perceptions, and L2 development. System, $41,472-483$.

Rassaei, E., \& Moinzadeh, A. (2014). Recasts, metalinguistic feedback, and learners' perceptions: A case of Persian EFL learners. Innovation in Language Learning and Teaching, 8 (1), 39-55.

Russell, J., \& Spada, N. (2006). The effectiveness of corrective feedback for second language acquisition: A meta-analysis of the research. In J. Norris \& L. Ortega (Eds.), Synthesizing research on language learning and teaching (pp. 131-164). Amsterdam: Benjamins.

Saito, K., \& Hanzawa, K. (2015). Developing second language oral ability in foreign language classrooms: The role of the length and focus of instruction and individual differences. Applied Psycholinguistics, 37(4), 813-840.

Sato, M. (2011). Constitution of form-orientation: Contributions of context and explicit knowledge to learning from recasts. Canadian Journal of Applied Linguistics, 14, 128 . 
Sato, M., \& Lyster, R. (2012). Peer interaction and corrective feedback for accuracy and fluency development: monitoring, practice and proceduralization. Studies in Second Language Acquisition, 34, 591-626.

Schmidt, R. (1990). The role of consciousness in second language learning. Applied Linguistics, 11, 206-226.

Schmidt, R. (1995). Consciousness and foreign language learning: A tutorial on the role of attention and awareness in learning. In R. Schmidt (Ed.), Attention and awareness in foreign language learning (pp. 1-63). Honolulu, HI: University of Hawai Press.

Schmidt, R. (2001). Attention. In P. Robinson (Ed.), Cognition and second language instruction (pp. 3-32).New York: Cambridge University Press.

Sheen, Y. (2004). Corrective feedback and learner uptake in communicative classrooms across instructional settings. Language Teaching Research, 8, 263-300.

Sheen, Y. (2008). Recasts, language anxiety, modified output, and L2 learning. Language Learning, 58,835-874.

Sheen, Y. (2010). Differential effects of oral and written corrective Feedback in the ESL classroom. Studies in Second Language Acquisition 32, 203- 234.

Sheen, Y. (2011). Corrective feedback, individual differences and second language learning. New York: Springer.

Sheen, Y., \& Ellis, R. (2011). Corrective feedback in language teaching. In E. Hinkel (Ed.), Handbook of research in second language teaching and learning (Vol. 2, pp. 593-610). New York: Routledge.

Simard, D., \& Jean, G. (2011). An exploration of L2 teachers' use of pedagogical interventions devised to draw L2 learners' attention to form. Language Learning, 61, $759-785$.

Straub, R. (1997). Students' reactions to teacher comments: An exploratory study. Research in the Teaching of English, 31, 91-119.

$\mathrm{Su}, \mathrm{T} .$, \& Tian, J. (2016).Research on corrective feedback in ESL/EFL classrooms. Theory and Practice in Language Studies, 6(2), 439-444,

Swain, M. (1995). Three functions of output in second language learning. In G. Cook \& B. Seidlhofer (Eds.), Principles and Practice in the Study of Language: Studies in Honour of H.G. Widdowson (pp. 125-144). Oxford: Oxford University Press

Tedick, D., \& de Gortari, B. (1998). Research on error correction and implications for classroom teaching. The ACIE newsletter, 1(3), 1-8.

Tsang, W. K. (2004). Feedback and uptake in teacher-student interaction: An analysis of 18 English lessons in Hong Kong secondary classrooms. RELC Journal, 35(2), 187-209.

Wang, Z. Q. (2014). Developing accuracy and fluency in spoken English of Chinese EFL learners. English Language Teaching, 7 (2), 110-118.

Yoshida, R. (2010). How do teachers and learners perceive correction feedback in the Japanese language classroom? Modern Language Journal, 94(2), 293-314.

\section{Copyrights}

Copyright for this article is retained by the author(s), with first publication rights granted to the Journal.

This is an open-access article distributed under the terms and conditions of the Creative Commons Attribution license (CC BY-NC-ND) (http://creativecommons.org/licenses/by-nc-nd/4.0/). 